\title{
A PRÁTICA DA LEITURA NO ENSINO FUNDAMENTAL
}

\author{
Cleidiane Gonçalves da Silva ${ }^{1}$ \\ Cristiane Moraes Pimentel ${ }^{2}$ \\ Eliane Maria de Lima Paixão ${ }^{3}$ \\ Jucilene Pinto de Campos ${ }^{4}$ \\ Sandra Aparecida Nogueira ${ }^{5}$
}

RESUMO: O presente artigo traz como temática central a leitura como hábito dos alunos do ensino fundamental, assim, o objetivo do presente trabalho é apresentar fatores que podem potencializar, no estímulo do desenvolvimento deste hábito. A metodologia adotada é de cunho qualitativo, sendo utilizada como instrumento de coleta de dados a revisão de literatura, assim, foi por meio de leituras e reflexões em artigos, revistas e livros científicos é que pode-se obter alguns resultados iniciais, tais como: a relevância da utilização de metodologias diferenciadas e a importância do papel do professor e da família neste processo.

Palavras chave: Leitura. Metodologias. Aprendizado.

ABSTRACT: This article brings as a central theme reading as a habit of elementary school students, thus, the objective of this work is to present factors that can enhance, in stimulating the development of this habit. The adopted methodology is of a qualitative nature, being used as a data collection instrument the literature review, thus, it was through readings and reflections in articles, journals and scientific books that some initial results can be obtained, such as: the relevance of using different methodologies and the importance of the role of the teacher and the family in this process.

Keywords: Reading. Methodologies. Apprenticeship.

\section{INTRODUÇÃO}

A leitura prepara o cidadão para a vida e estimular o indivíduo a um processo de leitura constante e agradável é de extrema importância na formação do verdadeiro leitor.

\footnotetext{
I Graduada em Pedagogia pela Universidade Norte do Paraná - UNOPAR, Especialista em Educação Infantil com Ênfase nos Anos Iniciais pela Faculdade FAIPE

${ }^{2}$ Graduada em Pedagogia pela Universidade Federal de Mato Grosso - UFMT, Especialista em Educação Especial e Inclusão pelas Faculdades Integradas de Várzea Grande - FIAVEC.

${ }^{3}$ Graduada em Pedagogia pelas Faculdades Mato-grossenses de Ciências Sociais e Humanas, Especialista em Educação Infantil e Alfabetização pelo Instituto Cuiabano de Educação - ICE.

${ }^{4}$ Graduação em Pedagogia pela Faculdade Afirmativo.

${ }^{5}$ Graduada em Pedagogia pela Universidade Luterana do Brasil - ULBRA, Especialista em Educação Infantil pela Faculdade das Águas Emendadas - FAE.
} 
Nesse sentido, desde cedo, os indivíduos têm contato com seus pares que podem ou não promover esse hábito em sua vida.

Desse modo, no início da vida escolar, as crianças têm contato com sua professora alfabetizadora, que tem como tarefa iniciar o processo de exploração infantil do universo da leitura.

Quando a leitura é estimulada pelos professores e praticada com mais intensidade, intervém em todas as áreas: intelectual, emocional e psicologicamente do aluno, refletindo sobre as manifestações escritas e orais, ou seja, sobre a ligação entre expressão e raciocínio.

\section{DESENVOLVIMENTO}

\section{I Leitura no ensino fundamental}

A leitura no ensino fundamental, geralmente noa remete aos anos iniciais, ao aprender a ler e a escrever, ao utilizar as letras, formar sílabas, criar palavras e então dizer que assim um sujeito deixa de ser analfabeto e passa ser alfabetizado. Especialmente nos anos iniciais desta etapa escolar, a preocupação dos educandos e da família geralmente, é para que a criança se torne alfabetizado e a cultura e o hábito da leitura por parte dos alunos, acaba sendo deixada de lado. Tal cultura deveria ser incentivada e vivida diariamente, pois a partir deste hábito constante é que se pode começar a construir verdadeiros leitores.

É comum observar as sérias dificuldades na habilidade da leitura e compreensão textual pelos alunos desta etapa escolar, pois os mesmos, não demonstram capacidade de abstrair as ideias mais relevantes do texto, apenas apresentam capacidade de decodificação simples, o que não significa que a compreensão tenha ocorrido.

Há fortes chances que, ao ingressarem no ensino médio, esses alunos não terão a capacidade de leitura crítica e reflexiva, tão desejada para esse nível de escolaridade (OLIVEIRA, 2005; SILVA, 2004). Esta realidade ocorre com um número alarmante de alunos, que por diversos fatores não conseguiram desenvolver esta capacidade primordial no decorrer da vida escolar.

Pois, de acordo com o resultado do Sistema de Avaliação da Educação Básica (SAEB) de 2017, apenas o percentual de $1,62 \%$ dos estudantes é que possuem um conhecimento adequado em Língua Portuguesa, é um número desastroso, levando em 
consideração que estes alunos estão concluindo a educação básica e prestes a ingressar o ensino superior (INEP/MEC 2018).

É fato que uma grande parte destes, concluem o ensino médio sem adquirir esta habilidade, tornando se um cidadão passivo de suas funções na sociedade e inclusive alienado da realidade social que o cerca. Os prejuízos para uma sociedade que não lê, são inúmeros, é por isso, que esta cultura deveria ser estimulada e desenvolvida desde a mais tenra idade, não esperando iniciar este hábito apenas após o período de alfabetização. $\mathrm{O}$ estímulo às práticas de leitura deveria acontecer diariamente para que isto, possa ser enraizado no indivíduo.

E ensino fundamental, este contato deveria ocorrer massivamente, pois aí está a base do futuro leitor, é nesta etapa da vida escolar, que é possível cultivar estas habilidades, se houvesse uma cultura de prática de leitura consistente em todos os anos do ensino fundamental, é possível que índices tão preocupantes pudessem ser evitados. No entanto, é um desafio diário, realizar práticas de leitura em salas de aulas com um grande número de alunos que não possuem uma estrutura social e econômica, que possa contribuir com este processo.

O sistema escolar por si só não é capaz de mudar esta determinação social, mas algumas escolas conseguem em maior ou menor medida que seus alunos tenham um aprendizado melhor que o esperado para suas condições sociais. Os alunos dessas escolas têm um desempenho acima da linha que define a determinação social. Ou seja, o efeito da escola é relevante e decisivo, embora não possa mudar completamente a determinação social (SOARES, 2007, p. 140).

De acordo com Paro (2017) a escola ainda, reproduz uma ideologia dominante, e que acaba legitimando a injustiça social tão presente no país, quando recoloca as pessoas nos lugares reservados pelas relações que se dão no âmbito da estrutura econômica. O fato é que apesar da melhoria de acesso das classes trabalhadoras à educação básica, a permanência e sucesso deste aluno ainda é um desafio.

O professor, que realizar um trabalho didático com práticas de leitura, por exemplo, em salas de aulas com um número excedente de alunos, com recursos físicos e materiais limitados, com uma carga horária de trabalho extensa e uma desvalorização profissional ainda muito evidente.

É preciso debater mais sobre essas situações que estão presentes diariamente na rotina docente e que acabam por produzir a escola pública atual, é necessário provocar a 
reflexão, sobre quais os fatores que contribuem para um resultado tão alarmante, como os do Saeb (2017) apresentado anteriormente.

Moreira (2009) diz que os cursos de formação docente ainda precisam de investimentos governamentais que possam favorecer a uma formação com bases teóricas e práticas que estejam pautadas nos documentos legais, que podem ser citados os $\mathrm{PCN}^{\prime} \mathrm{s}$ e as Diretrizes ao Ensino Técnico. É importante que o professor receba metodologias diferenciadas para se obter uma prática prazerosa de leitura, para tanto o professor deverá gostar de ler, de nada adiante querer incentivar o aluno se o próprio professor não tem o hábito da leitura.

É fundamental considerar os docentes como construtores de saberes, e como leitores, assim, é preciso que eles adquiram a habilidade de apropriação do conhecimento, valorizando uma transformação crítica de sua prática cotidiana. $O$ professor precisa estar ciente de sua responsabilidade para a formação do leitor, considerando a importância da leitura por toda a sua vida, é necessário que se ofereça um trabalho de qualidade e responsabilidade.

A prática de sala de aula, não apenas da aula de leitura, não propicia a interação entre professor e aluno. Em vez de um discurso que é construído conjuntamente por professores e alunos, temos primeiro uma leitura silenciosa ou em voz alto do texto, e depois, uma série de pontos a serem discutidos, por meio de perguntas sobre o texto, que não leva em conta se o aluno de fato o compreendeu. Trata-se, na maioria dos casos, de um monólogo do professor para os alunos escutarem. Nesse monólogo o professor tipicamente transmite para os alunos uma versão, que passa ser a versão autorizada do texto. (KLEIMAN 2000, p. 24).

As metodologias apresentadas devem ser trabalhadas de modo claro e objetivo, favorecendo a aprendizagem através da linguagem, porque o aluno mostrando interesse, já é um motivo suficiente para aumentar a construção do conhecimento e de habilidades de leitura.

Santos (2005) afirma que é necessário oferecer à criança atividades lúdicas, que possam despertar a curiosidade pelo que é fantasioso, por histórias que podem ou não, ser adaptadas, é importante, contudo, se que conte histórias. A construção de um bom leitor não acontece de um momento para o outro, é preciso muito empenho e dedicação contínua dos docentes, no desenvolver de sua ação pedagógica.

Para Carvalho (2002), o aprendizado da leitura se mostra de forma mais eficiente quando os leitores já apresentam um conhecimento sobre as tipologias textuais, as 
características, estruturas dos textos que podem ser trabalhados. Muitas vezes a diversidade textual apresentada aos alunos, acabam dificultando a compressão, devido a forma como se apresenta aos alunos, principalmente quando os leitores são iniciantes.

Com esse pressuposto, é importante que se trabalhe desde cedo com os alunos a língua escrita e as suas regras, de maneira moderada, sem exageros de cobranças, mas buscando oferecer condições para que os futuros leitores possam compreender os textos, tornando-se bons escritores. As variedades da tipologia textual ajuda na construção e ampliação na formação de leitores comprometidos e conscientes da importância da leitura. Dessa forma, a prática da leitura em sala de aula no ensino fundamental, é um grande desafio, que precisa ser vencido, apesar de todas as dificuldades, existem alguns fatores que poderiam potencializar e estimular este hábito, como poderá ser observado no próximo tópico.

\subsection{A prática da leitura}

A importância das teorias educacionais para o aproveitamento dos educandos no ensino fundamental é relevante, uma vez que, o educador não trata do ensino e aprendizagem como algo solto e inacabado, para o bom ensino deve haver uma articulação com conhecimentos teóricos e realidade em sala de aula.

Um elemento que potencializa a prática de leitura em sala de aula é a leitura coletiva, Vygotsky (1998) esclarece que deve se incentivar a integração dos alunos em grupos, para que assim o trabalho educacional possa ocorrer constantemente e que os nossos pensamentos são fruto da motivação, ao sentir necessidades específicas, desejos, interesses ou emoções, somos motivados a produzir pensamentos, ou seja, este elemento pode auxiliar na produção de conhecimento a partir de uma leitura compartilhada, pois torna o momento mais dinâmico e confortável para o compartilhamento de ideias.

$\mathrm{O}$ autor, tem como um dos seus pressupostos fundamentais a ideia de que o ser humano se constitui enquanto tal, a partir da interação social, é de que o funcionamento mental no ser humano é oriundo de processos sociais, pois não se pode estudar o comportamento do indivíduo em contexto isolado, mas em interação com outros indivíduos. É na leitura que se interpretam as imagens, os símbolos, os gestos, é na interação que se lê os sonhos expressos nos textos produzidos. 
Emília Ferreiro (1986) nos mostra a importância de conhecer os processos que as crianças constroem durante a alfabetização para depois compreender e interpretar o texto, por isso este é o segundo elemento potencializador da prática de leitura, conhecer e respeitar as fases de aprendizado do aluno, para que, a partir disso, possam ser oferecidas leituras que estejam de acordo com o processo em que os alunos estão vivenciando, para que assim, sintamse motivados nesta prática.

Todos os indivíduos são diferentes e essas fases poderão ocorrer em momentos diferenciados entre algumas crianças, cabe ao professor estar atento a cada processo individual e promovendo intervenções que pudessem ajudar a criança em seu processo de leitura.

Conhecer quais são esses processos de compreensão infantil dota o alfabetizador de um valioso instrumento para identificar momentos propícios de intervenção nesse processo. Aprender a interpretar, é um longo aprendizado que requer uma atitude teórica definida (FERREIRO, 1993, p. 25).

A leitura significa muito mais que decodificar as palavras segundo a autora, leitura é também interpretar a todas as situações que ocorrem ao nosso redor, onde o educando faz uma reflexão, interpretando entendendo seu mundo, a leitura é uma ampliação do conhecimento através da vivência do educando e sua prática, levando-o a descobrir e dominar a leitura, não apenas pelo seu valor, mas como fator de crescimento pessoal. Além do que, Solé (1998) afirma que o leitor precisa ser ativo, processar e examinar o texto buscando o objetivo daquela leitura, o que interferiria na interpretação e extração de informações por aquele leitor.

Quando começamos a estabelecer relações entre as experiências e a tentar resolver os problemas que se nos apresentam. Aí então estamos procedendo leituras, as quais nos habilitam basicamente a ler tudo e qualquer coisa (MARTINS, 1986, p. 17).

Desta forma, outro elemento potencializador para o ato de ler é aproximar a leitura da realidade e o mundo que o cerca, considerando sua bagagem de experiência trazidas de sua vivência fora da escola.

Para Piaget, (1978, 1990, 1994) o educando é o construtor do próprio conhecimento. Neste contexto, o educador deve se colocar na posição de mediador da relação educador objeto de conhecimento, de um facilitador da aprendizagem. Aprende-se fazendo, refazendo, recomeçando, mas também sobre o próprio fazer. Aprende-se o ler, lendo, relendo, ressignificando. 
Freire (1989) acredita na leitura como algo capaz de propor sentido amplo e de versas. Um homem não escolarizado é um leitor, pois interpreta e interfere no mundo que o cerca. Ler é algo independente da escola e do conhecimento intelectual. A partir desse pensamento o professor deve pôr em prática, situações em que levem os alunos a construir, aprofundar e ampliar seus conhecimentos, somente o professor pode inspirar aos alunos o desejo por uma leitura prazerosa, deixando bem claro que a leitura não deve ser memorizada mecanicamente, e sim, desafiadora, que nos ajude a pensar e observar a realidade.

Ler, segundo Freire (1989), não é caminhar sobre as letras, mas interpretar o mundo e poder lançar sua palavra sobre ele, interferir no mundo pela ação. Ler é tomar consciência. A leitura é antes de tudo uma interpretação do mundo em que se vive. Falar sobre ele, interpretálo, escrevê-lo, o autor concebia o ato de ler a partir da leitura do mundo, definido como o indivíduo percebe sua realidade.

Outro elemento potencializador, é o apoio e incentivo da família, pois, a criança necessita receber motivação para que a prática de leitura se concretize, uma vez que, a participação dos adultos durante esta fase de compreensão e conhecimento da leitura é extremamente importante, pois é a partir das expressões e hábitos cotidianos que a criança realiza o entendimento desse universo desconhecido.

\footnotetext{
Entretanto, cabe aos pais contribuírem para o desenvolvimento desse processo, mas na maioria das vezes as crianças não recebem o auxílio dos mesmos, pois estes também não o receberam no passado, e não detém conhecimento e até mesmo habilidades de contribuírem para com a formação de seus filhos; assim pais que leem formam crianças leitoras. É importante dizer também o quanto pode ser significativo que os pais leiam histórias para seus filhos ou folheiem com eles um álbum de literatura infantil, levando-os a dizerem o que imaginam que irá acontecer na página seguinte depois de virada (JOLIBERT, 1994, p. 129).
}

A criança que tem o incentivo dos pais na leitura desde cedo, é privilegiada em diversos fatores; ela aprende melhor, pronuncia com mais facilidade as palavras, amplia seu vocabulário, se expressa e comunica melhor:

[...] a relação entre o pensamento e a palavra não é uma coisa, mas um processo, um momento contínuo de vaivém do pensamento para a palavra e vice-versa [...] nesse 4 processo, a relação entre o pensamento e a palavra passa por transformações que, em si mesmas, podem ser consideradas um desenvolvimento no sentido funcional. O pensamento não é simplesmente expresso em palavras, é por meio delas que ele passa a existir (VIGOTSKY, 1995, p. 153). 
Através da leitura, a criança obtém melhor a criatividade, a imaginação e uma cultura de conhecimentos e valores fundamentais para sua vida. A leitura em família ajudará a criança estar mais preparada para os estudos futuros, para o trabalho profissional e para a vida. O processo de leitura com os pais deverá ser uma rotina, divertida e cheia de descobertas.

Os pais são mediadores indispensáveis no processo, portanto, mesmo depois de a criança aprender a ler, os pais devem continuar lendo para ela, pois a troca afetiva que se estabelece no contato com os livros favorece o envolvimento com a leitura.

É interessante estimular a criança a inventar histórias e criar os próprios livros, incentivando a troca de livros entre amigos, primos e vizinhos para ajudar o contato com umas variedades de maiores títulos. Habituar a criança com diferentes gêneros literários.

Procurar um momento especial da leitura, onde um tempo seja dedicado a leitura prazerosa, cada um lê o que é de seu interesse, e o outro momento voltado para a prática de leitura voltada para o desenvolvimento de conteúdo.

Segundo Duke e Pearson (2002) apud Cantalice (2004) existem estratégias de leitura consideradas relevantes, baseadas em pesquisas tidas como auxiliares no processo de leitura. São as seguintes: Predição, pensar em voz alta, estrutura do texto, representação visual do texto, resumo e questionamento.

Todas essas estratégias buscam ajudar no desenvolvimento da leitura, a partir do momento que fatos ou conteúdo do texto sejam utilizados com o conhecimento existente. O leitor verbaliza o pensamento enquanto lê, o professor auxilia os alunos a aprenderem a usar as características dos textos, como um procedimento auxiliar para compreensão e recordação do conteúdo lido. Na representação visual, ajuda os leitores a entenderem e organizarem algumas palavras enquanto imagem mental do conteúdo.

O resumo, é muito usado em sala de aula desde que tenha um objetivo específico, não como uma mera cópia do texto, mas facilita a compreensão geral do texto destacando as informações mais relevantes. Os Questionamentos, ajudam no entendimento do conteúdo da leitura, uma vez que permite ao leitor refletir sobre o mesmo. Neste aspecto, é importante que o professor antes de solicitar este tipo de atividade, explique e apresente técnicas para este tipo de trabalho para que o aluno tenha claro qual o objetivo e possíveis formas de executá-la. 
A partir da interpretação da leitura, o indivíduo pode conseguir fazer relações, argumentar, concluir, avaliar, podendo assim posicionar-se diante do que leu. $O$ conhecimento adquirido anteriormente pela criança auxilia na compreensão do texto, assim como as imagens que aparecem como auxílio ao texto. (PALÁCIOS; PIMENTEL; LERNER, 1998).

A partir do momento que o professor trabalhar de forma diferenciada a leitura, com várias estratégias poderá então haver em sala de aula um leitor eficiente que é aquele que: constrói perguntas enquanto lê e se mantém atento, seleciona índices relevantes para a compreensão, supre os elementos ausentes, complementando informações, antecipa fato, crítica conteúdo, reformula hipóteses, estabelece relações com outros aspectos do conhecimento, transforma ou reconstrói o texto lido, atribui intenções ao escritor.

O educador que faz uma leitura em voz alta, o aluno aprende que, ouvir a ler não é algo de desinteresse, mas sim participativo, onde o professor transforma essa leitura em algo dinâmico e que as crianças entrem no mundo imaginário do livro.

O professor pode fazer com que os alunos participem da leitura, através das imagens contidas no texto, podendo transformar essa leitura em uma representação da história, fazendo isso, leva as crianças a relacionarem também com a escrita.

Existem muitos outros elementos, que poderiam ser elencados como possíveis potencializadores no desenvolvimento do hábito da leitura no contexto do ensino fundamental, mas a partir, destes poucos já citados, pode-se iniciar uma reflexão sobre as possibilidades existentes a cerca do tema central discutido, assim, será apresentado a seguir, algumas considerações e apontamentos, que não podem ser considerados finais, mas iniciais para uma discussão e pesquisa futura muito maior.

\section{CONCLUSÕES}

Considerando a importância da leitura para o desenvolvimento do ser humano, é necessário estimular o prazer da leitura desde a infância, por isso este trabalho traz, deliberadamente, no início do texto, reflexões sobre as dificuldades cotidianas enfrentadas pelos professores da rede pública de ensino fundamental. Pois, ao se considerar a questão central, o contexto em que essas práticas ocorrem não pode ser ignorado, pois afeta significativamente o resultado final. 
Assim como não se pode ignorar que o desenvolvimento das habilidades e práticas da leitura é colocado pela sociedade em geral nas mãos dos professores do ensino fundamental, no entanto, a formação inicial desse profissional ainda precisa ser aprimorada e adaptada para que de fato o possam cumprir esta grande responsabilidade que lhes foi confiada.

Existem vários elementos de empoderamento que só poderiam ser bem executados se a formação inicial de professores fosse realizada com qualidade, pois esses profissionais precisam ter princípios pedagógicos básicos claros em sua prática, defendidos pelos autores citados no texto. Da mesma forma, é necessária a participação da família em ações que funcionem como fatores de potencialização na construção de um sujeito de leitura. É importante refletir que são inúmeros os elementos que podem contribuir para a tão esperada formação do sujeito da leitura, conforme apresentados ao longo do texto, mas talvez essas estratégias fossem mais fáceis de implementar se a sociedade do país já tivesse amadurecido a cultura do leitor, a leitura, uma vez que ainda vivemos em um contexto em que o livro e o ato de ler não gozam de prestígio popular.

A procura por estratégias e ferramentas que possam melhorar o índice de aproveitamento português dos alunos do ensino básico, mas se a sociedade já tivesse desenvolvido a cultura da leitura, os resultados seriam certamente melhores, uma vez que esta capacidade se desenvolveria naturalmente.

A leitura não seria vista como uma obrigação, nem como uma atividade metódica e frustrante, mas como algo que leva à reflexão, à imaginação, à curiosidade e à paixão. É uma exigência da sociedade, sem ela não é possível formar cidadãos críticos e conscientes de seu papel e classe social. Portanto, uma sociedade que não lê pode estar condenada à estagnação e ao aprisionamento simbólico, o que também pode levar a perigosas regressões. Para amenizar essas graves consequências que têm ocorrido pela falta desse hábito primordial, é necessário envolver políticas públicas que realmente valorizem a educação pública, o ensino fundamental, e invistam prioritariamente neste pilar da sociedade, hoje tão frágil. 


\section{REFERÊNCIAS}

CÂMARA, Marineuza Tramontin. A importância da leitura na alfabetização. UNESC. Criciúma, 2009.

CARVAlHO, M. Guia prático do alfabetizador. São Paulo, SP: Ática, 2002. CANTALICE, M. L. Ensino de estratégias de leitura. Psicol. Esc. Educ. (Impr.) vol.8 no.I Campinas June 2004.

CONSTANCIO, A. S. O.; MENDONÇA, D. M.; PAIVA, M. C.; PRINCE, A. E. A importância do incentivo ao hábito da leitura. Anais... XIII Encontro Latino Americano de Iniciação Científica e IX Encontro Latino Americano de Pós-Graduação Universidade do Vale do Paraíba. 2009.

FERREIRO, E; TEBEROSKY, A; LICHTENSTEIN, D M. Psicogênese da língua escrita. Artes Médicas, 1986.

FERREIRO, E. Com todas as letras. Tradução de Maria Zilda da Cunha Lopes; retradução e cotejo de textos Sandra Trabucco Valenzuela. 1993.

FREIRE, P. A importância do ato de ler. São Paulo, Cortez, I989.

JOLIBERT, J. col. Formando crianças leitoras. (Trad. Bruno Charles Magne). 1994.

KLEIMAN, Â. A concepção escolar da leitura. In: Oficina de leitura. Teoria e Prática. $7^{\underline{a}}$ ed. Campinas: Pontes, 200o. Horizontes - Revista de Educação, Dourados-MS, v. 7, n. 13, p. 24-36, jan./jun. 2019. Faculdade de Educação (FAED) da Universidade Federal da Grande Dourados (UFGD)

MARTINS, M. A; MENDES, A. Q. Leitura da imagem e leitura da escrita: Um estudo psicogenético das diferentes conceptualizações e estratégias de leitura em crianças de idade pré-escolar. Análise Psicológica, v. 5, p. 45-65, 1986.

MOREIRA, T. M. Avanços, obstáculos e superação de obstáculos no ensino de português no Brasil nos últimos to anos. 'Ensino de escrita na escola', em outubro de 2009 . Disponível em http://w3.ufsm.br. Acessado em Io/II/2021.

PALACIOS, A. de P; PIMENTEL, M. M; LERNER, D. de Z. Compreensão da leitura e expressão escrita. A experiência pedagógica. Porto Alegre: Artmed, 1998.

PARO, Vitor Henrique. Gestão democrática da escola pública. Cortez Editora, 2017. PIAGET, J. et al. Introducción a la epistemología genética. 1994. 
PIETRE, E. Práticas de leitura e elementos para a atuação docente. 2007. SANTOS, L. W. dos. Leitura na escola e formação do leitor. Anais... IV Encontro de Literatura Infanto e Juvenil. Rio de Janeiro, UFRJ, 2005.

SEIXAS, H. O prazer de ler. Casa da Palavra, 201.

SOLÉ, I. Estratégias de leitura. 6ae ed. Porto Alegre: Artmed, 1998.

STANO, Rita de Cássia M. T. O caminho de um grupo de formação continuada docente: do compartilhamento de práticas docentes para uma pedagogia da e para a autonomia. Educ. Rev., Curitiba, n. 57, jul/set., 2015.

VYGOTSKY, L. S. Pensamento e linguagem. Tradução de Jéferson L. Camargo. 2.ed. São Paulo: M. Fontes, 1998. 